\title{
Kepedulian Pemuda Dalam Tradisi Basilawek Pada Upacara Kematian Di Kenagarain Kapelgam Kecamatan Bayang Kabupaten Pesisir Selatan
}

\author{
Hari Gusmina,Isnarmi,Nurman \\ Program Studi Pendidikan Pancasila dan Kewarganegaraan \\ FIS Universitas Negeri Padang \\ E-mail :harigusmina@gmail.com
}

\begin{abstract}
ABSTRAK
Tujuan penelitian ini menganalisis kepedulian Pemuda dalam Tradisi Basilawek pada Upacara Kematian di Kenagarian Kapelgam Kecamatan Bayang Kabupaten Pesisir Selatan. Penelitian ini menggunakan pendekatan kualitatif dengan, penentuan informan dalam penelitian memakai teknik Purposive sampling, teknik pengumpulan data adalah wawancara, observasi, dan studi dokumentasi. Uji keabsahan data dilakukan melalui teknik trianggulasi sumber data, dianalisis dengan cara reduksi data, penyajian data dan penarikan kesimpulan. Hasil penelitian menunjukan bahwa dari segi pelaksanaan tradisi basilawek di Kenagarain Kapelgam mengalami perubahan pada waktu pelaksanaan, dahulunya dilaksanakan sesudah shalat magrib namun saat ini dilaksanakan sesudah shalat isya. Perubahan juga terlihat dalam pembacakan surat silawek, dahulunya surat dibacakan sesuai dengan hari meninggalnya almarhum, saat ini surat yang dibacakan sekehendak hati pemuda. Kepedulain pemuda dalam tradisi basilawek pada upacara kematian di Kenagarain Kapelgam terlihat berkurang, belum semua pemuda mengikuti tradisi basilawek. Upaya untuk mempertahankan tradisi basilawek yaitu mengajak dan menghimbau kembali pemuda pemudi untuk mengikuti basilawek, dan memberi pengetahaun sejak dini kepada generasi penerus (anak-anak), serta diadakan pelatihan agar tradisi ini tetap berjalan semestinya untuk lebih baik kedepannya.
\end{abstract}

\section{Kata Kunci : Kepedulian, Pemuda, Tradisi Basilawek}

\section{ABSTRACT}

The purpose of this research describes the concern of youths in Basilawek tradition of funeralceremony in Kapelgam village, Bayang sub district, Pesisir Selatan regency. The approach from this research is qualitative hu using purposive sampling technique to determine the informants. Data collection wa te through interview, observations, and documentation studies. The test of data validity is done through triangulation technique of data source, analyzed by reduction of data, presentation of data, and withdrawal of conclusions. The results shows that in terms of implementation of Basilawek tradition at Kapelgam village has changed during the time of execution, formerly it used to performed 
after maghrib prayer, but now it is done after isya prayer. The changes are also seen in reading of letters of silawek, formerly letters were read in accordance with the day of the deceased's people, but now letters are read at the will of youth's heart. Concerning of youth in basilawek tradition at the funeral ceremony at Kapelgam village is looked reduced because not all of youths follow basilawek tradition. The efforts to maintain basilawek tradition are done by inviting and calling back young men and young women to follow basilawek tradition, giving early knowledge to the next generation (children), and giving training to keep this tradition running well for the better future.

\section{Keywords: Concern, Youths, Basilawek Tradition}

\section{PENDAHULUAN}

Pemuda merupakan pewaris generasi yang seharusnya memiliki nilai-nilai luhur, bertingkah laku baik, berjiwa membanguan, cinta tanah air, memiliki visi dan tujuan positif. (Pramudyasari Nur Bintari, 2016:1). Penegrtian pemuda menurut undang-undang No. 40 tahun 2009 adalah warga negara indonesia yang memasuki periode penting pertumbuhan dan perkembangan yang berusia 16 (enam belas ) sampai 30 (tiga puluh tahun.

Pemuda generasi sekarang sangatlah berbedaberbeda apabila dibandingkan dengan generasi terdahulu, dilihat dari segi pergaulan maupun sosialisasinya, pola berfikir, dan cara menyelesaikan masalah yang sedang dihadapinya. Sedangkan

pemuda zaman sekarang masih terkesan acuh terhadap masalahmasalah sosial yang ada dilingkungannya dan hanya memikirkan kepentingan diri sendiri. Sebagaimana yang peneliti lihat di Kenagarain Kapelgam Kecamatan Bayang Kabupaten Pesisir Selatan dimana pemudanya kurang bersosialisasi dengan masyarakatbserta kurangnya kesadaran dan terhadap tradisi dan kebiasaan yang dilakukan didalam lingkungan masyarakat, seperti yang peneliti lihat dalam Tradisi Basilawek.

Tradisi basilawek merupakan Tradisi turuntemurun yang dilakukan dimasyarakat Kenagarian Kapelgam, tradisi Basilawek ini dilakukan pada upacara kematian. Basilawek adalah sama hal nya dengan membaca surat yasin, tetapi dalam Basilawek itu ada surat untuk Basilawek nya. Penyelenggaraan upacara kematian Basilawek di 
Kenagarian Kapelgam di adakan pada malam hari setelah mayat di kuburkan. (wawancaraawal dengan bapak Kardiman pada tanggal 20 Mei 2016).

Proses basilawek itu di sediakan secerek air di tengahtengah anggota Basilawek yang mana anggota basilawek itu adalah pemuda pemudi masyarakat di Kenagarian Kapelgam, sebelum dimulai ketua silawek meminta izin terlebih dahulu kepada tuan rumah, setelah diizinkan barulah dimulai membacakan surat Al-fatihah dan terus Basilawek, sesudah membaca surat silawek itu di iringi membaca ayat suci al-quran dan ditutupi dengan doa, Selesa9 membacaka do'a barulah ketua silawek meminta izin pulang kerumah masing-masing. Kegunaan air yang disediakan di tengah-tengah anggota silawek itu adalah untuk mendinginkan almarhum di dalam kuburan, air itu disiramkan kekuburan pada pagi harinya mulai dari kepala sampai ke kaki dengan membacakan shalawat nabi tiga kali. (wawancara awal dengan bapak Jasrianto pada tanggal 25 Mei 2016).

Pada masyarakat Nagari Kapelgam apa bila yang meninggal itu orang yang sudah baligh maka pelaksanaan basilaweknya 3 malam tetapi kalau yang meninggal itu anakanak basilaweknya 2 malam, jika keluarga almarhum nya itu meminta untuk menambah basilaweknya maka akan di penuhi permintaannya itu oleh anggota silawek.

Tujuan basilawek ini dilakukan sebagai silaturrahmi untuk almarhum yang ditinggalkannya, artinya dengan datang nya anggota basilawek itu kerumah duka untuk basilawek maka keluargaa yang di tinggalnya setidaknya bisa tenang mendengarkan bacaan silawek dari anggota basilawek itu. Tradisi ini merupakan kebiasaan turun temurun sekelompok masyarakat berdasarkan nilainilai budaya masyarakat yang bersangkutan.

Pada saat ini pemuda jarang mengikuti basilawek, dan terkadang dia hanya pergi ketempat tertentu saja misalnya, karib kerabat terdekatnya, padahal dahulunya tidak seperti itu, kalau sudah terdengar ada orang yang meninggal pemudapemudi tersebut pada malamnya langsung pergi untuk basilawek tanpa di perintah. Bahkan pada saat ini para pemuda tidak tahu apa maksud dan tujuan basilawek 
itu, para pemuda tersebut hanya ikut-ikutan saja dia tidak memahami apa maksud dan tujuan dari basilawek itu sendri.

Dari beberapa uraian diatas maka peneliti merasa masalah tersebut penting untuk diteliti karena sebagai sesama masyarakat harus memiliki solidaritas. Olah karena itu peneliti memberi judul penelitian ini “Peran Pemuda Dalam Tradisi Basilawek Pada Upacara Kematian Di Kenagarian Kapelgam Kecamatan Bayang Kabupaten Pesisir Selatan.".

\section{METODE PENELITIAN}

Metode penelitian yang peneliti digunakan dalam penelitian ini adalah kualitatif yaitu penelitian yang menggambarkan atau mendeskripsikan kepedulian Pemuda dalam Tradisi Basilawek pada Upacara Kematian di Kenagarian Kapelgam Kecamatan Bayang Kabupaten Pesisir Selatan. Jenis data yang digunakan adalah data primer dan sekunder, dengan pengumpulan data memalui observasi, wawancara dan studi dokumentasi. Teknik pengujian keabsahan data melalui teknik triangulasi sumber data. Analisis data teknik reduksi data dan verifikasi data.

TEMUAN DAN PEMBAHASAN

1. Proses Pelaksanaan Tradisi Basilawek Pada Upacara Kematian Di Kenegarian Kapelgam Kecamatan Bayang Kabupaten Pesisir Selatan.

Menurut Mursal Esten (1993:11) berpendapat tradisi adalah kebiasaan turun temurun sekelompok masyarakat berdasarkan nilai-nilai budaya masyarakat yang bersangkutan. Menurut Badudu Zain (1994:54) tradisi adalah adat kebiasaan yang dilakuan turun temurun dan masih dilakukan dalam masyarakat di setiap tempat atau suku-suku berbeda-beda. Selain itu tradisi dikaitkan sebagai adat kebiasaan turun temurun dari nenek moyang yang masih dijalankan dalam masyarakat. Seperti halnya tradisi basilawek merupakan tradisi turuntemurun yang dilakukan masyarakat Nagari Kapelgam, yang sudah menjadi kebiasan masyarakat Nagari Kapelgam, tradisi basilawek ini dilakuan setelah mayat dikuburkan.

Pergeseran dan perubahan adat seperti pepatah Minangkabaumangatakan "Sakali aie gadang,sakali tapian barubah" 
(sekali air besar sekali tapian berubah). Setiap kehidupan masyarakat manusia senantiasa mengalami sesuatu perubahan ( Abdulsyani 2007: 162). Dari hasi temuan waktu pelakanaan tradisi basilawek yaitu pada malam hari setelah shalat isya, yang mana pada dahulunya waktu pelaksanaan tradisi basilawek yaitu sesuadah shalat magrib, lama waktu pelaksaan silawek padadahulunya 15 menit dan sekang lama waktu membacakan bacaan silawek 30 menit, terjadi perubahan waktu pelaksanaan silawek di sebabkan kerana pemuda dan pemudi yang membacakan bacaan silawek pada dahulunya anggota basilawek benar-benar membacakan bacaan silawek dan pada saat sekarang ini anggota basilawek kurang serius dalam membacakan bacaan silawek.

Proses pelaksanaan tradisi basilawek terlebih dahulu ketua basilawek meminta izin kepada tuan rumah bagaimana apakah sudah bisa dimulai untuk basilawek, setelah di izinkan baru lah anggota basilawek memulai basilawek yang mana di mulai dari membaca surat Al-fatihah dan terus basilawek, dimana dalam membacakan bacaan silawek terjadi perubahan dalam membacakan bacaan silawek, yang mana pada dahulunya bacaan silawek sesuai dengan hari meninggalnya almarhum \ almarhumah dan pada saat sekarang ini tidak sesuai lagi dengan hari meninggalnya almarhum \almarhumah, karena disebabkan anggota basilawek ingin cepat pulang,dan ada sebagian dari anggota basilawek anak-anak jadi anggota basilawek tersebut memilihsurat yang mudah untuk dibacakan agar anak-anak bisa mengikuti anggota yang lain. Setalah bacaan silawek selasai beberapa dari anggota basilawek membacakan ayat suci Al-quran dbarulah ditutupi dengan do'a, setalah pembacaan do'a selesai barulah ketua silawek meminta izin pulang kerumah masing masing.

2. Kepedulian Pemuda Dalam Tradisi Basilawek Pada Upacara Kematian Di Kenagarain Kapelgam Kecamatan Bayang Kabupaten Pesisir Selatan.

Dalam Kamus Besar Indonesia, menurut Poerwodarminta(1993), peduli dapat di artikan sebagai memperhatikan, menghiraukan, mengindahkan dan mencampuri. Peduli sebagai kata dasar kepedulian, pada hakekatnya 
menunjukan adanya perhatian terhadap sesuatu. Pengertian Pemuda menurut Undang Undang No. 40 tahun 2009 adalah warga negara Indonesia yang memasuki periode penting pertumbuhan dan perkembangan yang berusia 16 (enam belas) sampai 30 (tiga puluh) tahun.Pemuda merupakan pewaris generasi yang seharusnya memiliki nilai-nilai luhur, bertingkah laku baik, berjiwa membangun, cinta tanah air, memiliki visi dan tujuan positif (Pramudyasari Nur Bintari, 2016:1). Jadi dapat disimpulkan bahwa kepedulian pemuda dalam tradisi adalah adanya perhatiaan generasi penerus (pemuda) terhadap suatu tradisi atau kebiasaan yang telah dilakukan secara turun temurun seperti tradisi basilawek di Kenagarian Kapelgam Kecamatan Bayang Kabupaten Pesisir Selatan.

Dari hasil temuan penelitian kepedulian pemuda dalam tradisi basilawek pemuda kurang peduli dalam tradisi basilawek dimana terlihat tidak semua pemuda tersebut yang mnegikuti basilawek, dimana pemuda tersebut harus di ingat-ingatkan terlebih dahulu kalau mau pergi basilawek, dan harus dipanggilpanggil untuk pergi basilawek, padahal tradisi basilawek ini sudah merupakan tradisi yang dilakukan secara turun-menurun dan pemuda tersebut kurang kesadarannya selaku pemuda di Kenagarian Kapelgam, pada dahulunya pemuda pemudi tidak perlu di ingat-ingatkan atau di panggil-panggil untuk pergi basilawek, kalau sudah terdengar orang meninggal pemuda tersebut langsung malamnya pegi basilawek kerumah duka. Jadi dapat disimpulkan bahwa kurangnya kepedulain pemuda dalam tradisi basilawek.
3. Upaya
Untuk Mempertahankan Tradisi Basilawek Dalam Upacara Kematain.

Adapun upaya untuk mempertahankan tradis pada upacara kamatian di Kenagarain Kapelgam Kecamatan Bayang Kabupaten Pesiair Selatan Menurut kamu Bahasa Indonesia (1994:751) menyebutkan pengertian upaya adalah tindakan yang dilakukan seseorang, untuk mencapai apa yang di inginkan atau merupakan sebuah strategi. Upaya adalah serangkaian langkah atau cara yang ditempatkan untuk mencapai suatu maksud atau tujuan. Sedangkan upaya mempertahankan adalah suatu 
langkah , cara untuk mempertahankan atau menjaga sesuatu supaya tetap utuh dan menjadi lebih baik. Nainul Khutniah (2013:24).

Dari hasil temuan peneliti upaya untuk mempertahankan tradisi sesaui dengan pendapat diatas di Kenagarain Kapelgam yaitu mengajak kembali dan menghimbau pemuda pemudi untuk mengikiti basilawek, memberikan pengetahuan silawek sejak dini kepada generasi penerus (anak-anak) dengan cara mengajak anak-anak untuk ikut serta dalam acara basilawek, dan juga di adakan pelatihan untuk mempertahankan tradisi. agar tradisi basilawek ini tetap berjalan semetinya dan lebih baik kedepanya.

\section{KESIMPULAN}

a. Proses pelaksanaan basilawek pada upacara kematian di Kenagaraian Kapelgam Kecamatan Bayang Kabupaten Pesisir Selatan. Terjadi perubahan waktu pelaksanaan dari shalat magrib ke shalat isya, dan perubahan dalam membacakan surat sialwek yang mana dahulunya sesuai dengan hari meningalnya dan sekarang sekehendak hati anggota itu saja.

b. Kepedulian pemuda dama tradisi basilawek pada upacara kematian di Kenagarain Kapelgam Kecamatan Bayang Kabupaten Pesisir Selatan pemuda kurang peduli dalam tradisi basilawek, dilihat dari tidak semuannya yang mengikuti basilawek.

c. Upaya untuk mempertahankan tradisi basilawek pada upacara kematian di Kenagaraian Kapelgam Kecamatab Bayang Kabupaten Pesisir Selatan yaitu mengajak kembalai dan menghimbau pemuda untuk basilawek, dan memberi pengetahuan sejak dini kepeda generasi penerus (anak-anak) serta diadakannya pelatiahan, agar tradisi ini tetap berjalan semestinya dan lebih baik kedepannya. 
$50 \mid$

Kepedulian Pemuda dalam..

DAFTAR PUSTAKA

Abdulsyani. 2007. Sosiologi Skematika Teori Dan Terapan.:Jakarta:Bumi Aksara.

Badudu ,J.S dan Z.M Zain.2007. Kamus Umum Bahahasa Indonesia. Jakarta: Balai Pustaka.

Mursal Esten.1993. Minangkabau Tradisi dan Perubahan. Jakarta: Angkasaraya

Nur Bintari, Pramudyasari. 2016. Peran Pemuda Sebagai Penerus Tradisi Sambatan Dalam Rangka Pembentukan Karakter Gotoroyong, Jurnal Pendidikan Ilmu Sosial.Vol25, No 1 Juni 2016

Poerwadarminta, W.J.S. 2003. Kamus Umum Bahasa Indonesia. Jakarta: Balai Pustaka

Republik Indonesia. Undang-Undang Nomor 40 Tahun 2009 Tentang Kepemudaan.

Khutniah, Niral. 2013. Upaya Mempertahankan Eksistensi Tari Kridha Jati di Sanggar Hayu Kelurahan Pengkol Kecamatan Jepara Kabupaten Jepara. Skripsi. Universitas Negeri Semarang 